\section{Decommission dental decay}

Transform the way you manage dental caries with the CALCIVIS system.

The CALCIVIS system uses a luminescent photoprotein to detect free calcium ions as they are released from actively demineralising tooth surfaces. It displays visual evidence of early demineralisation as a glowing map at the chairside in time to initiate preventive measures and before early carious lesions have a chance to progress to the cavitational stage.

This early detection system is revolutionising preventive dentistry with the visualisation of demineralisation.

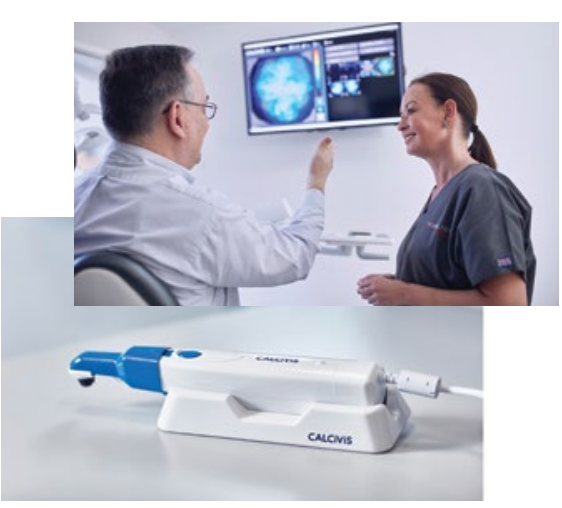

Contact CALCIVIS now and join the crusade to decommission dental decay.

For more information visit www. calcivis.com, call on 01316585152 or email at info@calcivis.com.

\title{
One month to go
}

BDIA Dental Showcase takes place next month (17-19 October) and if you haven't already registered, now's the time to do so!

All members of the team will benefit from the breadth of educational opportunities. The Dental Update Theatre will host will be running back-to-back throughout the three days or head to selected exhibitor stands for even more CPD opportunities.

For many people the draw of this event is the unrivalled plethora of dental suppliers all conveniently placed under

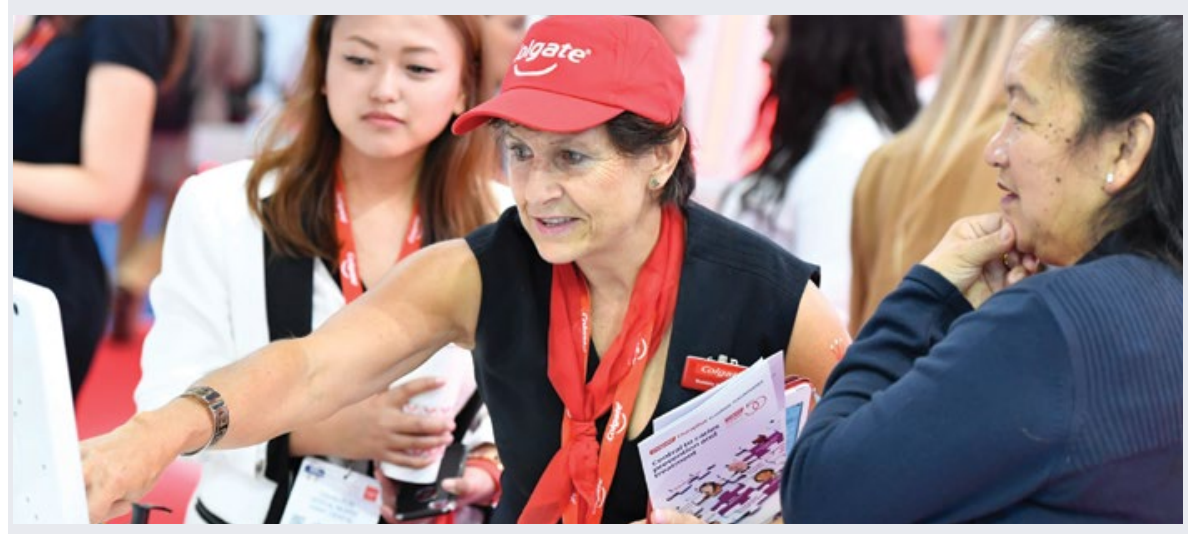

a range of experts offering guidance on both clinical and non-clinical topics. Hear from leading academics on lecture topics covering everything from acute dental trauma to the updated IRMER regulations and its implications for dental practitioners. All lectures are designed to provide practical and relatable information, so you have the relevant knowledge and skills to apply to your own surgery. Businesscentric sessions will also be on the agenda, covering areas such as P\&L, tax efficiency and pension planning. You can also enjoy lectures in the Innovation Theatre, which one roof. As in all aspects of life, technology is evolving at a rapid pace and BDIA Dental Showcase will show you the latest developments as well as giving you the chance to do some research before you make an investment. You will be able to explore the services of a range of dental exhibitors without the usual interruptions you might experience with a daytime appointment. Typically, 75\% of exhibitors at BDIA Dental Showcase also offer special discounts, offers or samples.

To register free visit dentalshowcase. com/register.

\section{Are you worried about bad reviews?}

We all make buying decisions based on reviews; the same goes for patients when they are choosing a dental practice.

EasyReview Pro will generate high volumes of fresh online reviews, on the platforms of your choice - you are in control!

In just ONE month, a practice using EasyReview Pro obtained:

- One hundred and thirty-five new reviews

- A $400 \%$ increase in Google reviews

- A $30 \%$ increase in web traffic!

EasyReview Pro will set it up so you can sit back and watch your online reputation soar.

Contact Dental Design for full details of EasyReview Pro and to get your FREE trial. To find out more about Dental Design's services, visit: https://dental-design-products.co.uk/, email enquiries@ dental-design.co.uk or telephone 01202 677277.

\section{Lexcel accreditation three years running}

FTA Law have been awarded Lexcel accreditation by the Law Society of England and Wales for the third year running. Lexcel accreditation is recognised in the legal profession as the quality mark for excellence in legal practice management and client care with only the top $18 \%$ of law firms in England and Wales being recognised with accreditation.

FTA Law are a full service independent law firm providing bespoke legal solutions to the healthcare sector. Founded by experienced dental solicitors Thomas Coates (Managing Director) and Sarah Buxton (Head of Dental Employment Law and HR), the firm demonstrates many years' experience in advising dentists, practice owners and other industry professionals. Services include practice sales and purchases, business advice, employment/ HR law and dispute resolution.

FTA Law specialist teams embrace new and dynamic ways of offering legal services focusing on absolute transparency of fees and a high level of prompt and efficient service tailor made to clients. More details about FTA Law are available at www.fta-law.com. 